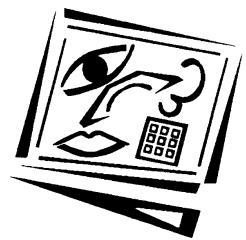

\title{
The power of the $6^{\text {three }}$ model for enhancing academic teachers' capacities for effective online teaching and learning: Benefits, initiatives and future directions
}

\author{
Stephen Segrave, Dale Holt and James Farmer \\ Deakin University
}

\begin{abstract}
To gain the full educational benefits of the major new investments in corporate technologies supporting online teaching and learning it is argued that a strategic, systems based approach to academic professional development (APD) is required. Such an approach requires a clear view of the key areas of potential and enduring teaching and learning benefit which can be realised from online developments, including an understanding of the changing role of the academic teacher in higher education, the identification of the desired professional capacities to educate online, and the implementation of a number of coordinated initiatives to develop these professional capacities in order to engage constructively with the learning and technology opportunities. Based on previous work, we propose a $6^{\text {three }}$ model of Academic Professional Capacities Development for effective APD of online teaching and learning. The model can help inform the actions of policy makers, executives and practitioners in ways that promote an authentic learning organisation.
\end{abstract}

\section{Introduction}

With ever increasing institutional investments in corporate technology infrastructure, the move to online education is accompanied by a raft of online teaching and learning policies carrying the imperative of engaging more broadly and deeply with the technologies. These include learning management systems, digital object management systems, synchronous communication technologies, streaming technologies and so on. This imperative for more systematic engagement with the new corporate technologies has led to a strongly perceived need for professional development programs to support academic teaching staff in their appropriate use of the online environment to support their students' learning. These programs go hand in hand with the deployment of the new 
solutions and focus on the use of various features of the technology to support various functions of the educational enterprise. Such programs in part need to deal with the necessities of learning to use the technical aspects of the technology, often in the context of the institution moving staff from legacy systems to newly acquired one(s). While necessary, these elements of such programs are not of themselves sufficient to take full educational advantage of the newly acquired systems.

Holt and Segrave (2003) have argued that the central challenge for universities investing substantially in new corporate technology infrastructure is to create and sustain quality e-learning environments of enduring value for teachers and learners. Six key areas of potential value adding were identified for critical reflection in relation to the role of the academic teacher and other parties in the educational enterprise. Assuming the utility of these six possible areas, the challenge is to establish an organisational culture conducive to the development of professional capacities supportive of advancing these areas. Beyond current efforts to train staff to use the features of learning management systems, we argue that strategic academic professional development must come to the fore. We examine six strategic APD initiatives in support of six areas of potential value adding, relating to six major professional capacities: our $6^{\text {three }}$ model of Academic Professional Capacities Development for enhancing online teaching and learning across the institution. This model is illustrated in Figure 1.

The value to APD professionals in using the $6^{\text {three }}$ model is its depiction of the constant flux and interactions experienced when dealing with the 6 elements in each of the three fields. Rather than being a mathematical expression of fixed value from fixed relationships, the $6^{\text {three }}$ model is contingency based, and properly reflects the imperative for APD professionals to act strategically in recognising and optimising the alignments of elements in their local contexts. It also calls for expert judgments about optimal APD courses of action to improve academic teachers' professional capacities. Our own University's attempts to put in place these types of initiatives are considered illustrative of the challenges of developing a learning organisation culture conducive to creating and sustaining quality e-learning.

\section{Background}

Holt and Thompson (1998), drawing on the MIT90s strategic framework for managing IT (as used by DEETYA 1997), critically examined the five components of managing information and communications technologies (ICT) in relation to open and distance education, namely: Strategy, Technology, Structure, Management Processes and Individual Skills and 
Roles. This examination was undertaken at a time of great strategic and technological change and flux in the system. Holt, Rice, Bowly and Smissen (2001) reported on the move towards institution wide approaches to the establishment of corporate technology infrastructure to support online teaching and learning. During the last five years in universities there appears to have been a settling of the technological infrastructure around the institutional adoption of, for example, learning management systems, and this contrasts with the more turbulent period of technological development and adoption reported in the 1990s by Holt and Thompson (1998).

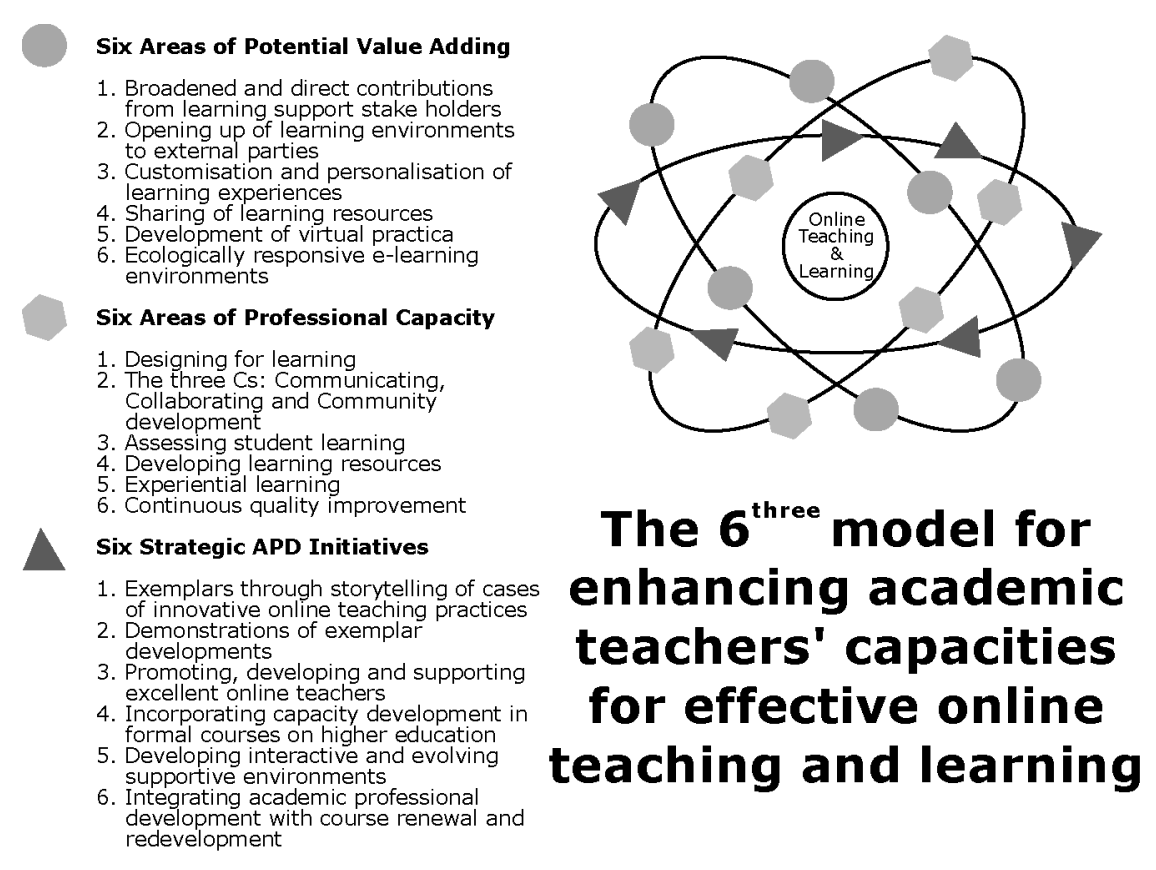

Figure 1: The $6^{\text {three }}$ model of academic professional capacities development

Moreover, at least at Deakin University, there has been a sharp strategic focus on determining online teaching and learning objectives, strategies and future implementation plans (see Deakin University Strategic Plan 2004 Taking Deakin University Forward, Deakin University Operational Plan 2004 and 'Deakin Online' Management Plan 2003-2007). While Strategy and Technology have gained greater clarity and direction in recent years, there still remain ongoing shifts in Structures and Management Processes in undertaking the new implementation agendas. Importantly, Individual Skills and Roles remain problematic, particularly in regard to the 
professional capacities required to make the best use of the investments in major new corporate technology infrastructure. Deakin has defined three levels of online presence: Basic, Extended and Wholly Online (see Deakin University Online Technologies in Courses and Units Policy). While the objective of providing every undergraduate unit with a Basic presence in the University's new Learning Management System (LMS), called Deakin Studies Online (DSO), has been achieved, the higher levels of digital and online development relating to Extended and Wholly Online remains challenging to say the least.

The University Strategic Plan to ensure that every undergraduate student enrolled from 2004 undertakes at least one unit wholly online, irrespective of their mode of enrolment, and requiring that no face to face teaching be offered as part of the experience, provides a new context for major innovation. At the beginning of 2004 the University's Pro Vice-Chancellor (Online Services) advocated responses that are not rote and mechanistic but sensitive to the needs of different disciplines and student cohorts. This wholly online experience must develop student attributes in ways that would not be possible through other types of learning environments supported by classroom teaching. So far it is planned for 20-30 such units to be offered in this form between 2004 and 2006.

\section{Current approaches to developing staff skills}

For the University to achieve the objective of all undergraduate units having a Basic DSO presence by the beginning of 2004, a large scale DSO training program was instituted over 2003 into 2004. Consistent with other such programs, this was targeted at developing a general overview of the University's new LMS and its various features, with additional specialised training on features novel to the new system and not used at Deakin previously. Much of the training was directed at ensuring that staff could operate effectively in the Basic DSO environment through the provision of in person training on Deakin's various campuses. Additionally, this in person training was augmented by a basic online DSO module and a staff support website [http://www.deakin.edu.au/teachlearn/dso/]. Holt and Segrave (2003) acknowledge the importance of this type of staff training in the context of systems migration and the appointment of a significant number of new staff to the institution in 2003. However, they were also keenly alert to: the emerging agendas around Extended and Wholly Online developments; the more fundamental issues relating to broader areas of potential e-learning value for teachers and learners; and the changing role of the academic in the system as driver of valuable change. Marsick and Watkins (1990, p.4) make a useful distinction between training and learning in this respect: 
By emphasising learning rather than training, we do not intend to devalue the importance of appropriate structured learning activities. However, we believe that an overriding interest in how best to organise learning through training has taken attention away from the natural opportunities for learning that occur every day in a person's working life. Training usually refers to short-term activities that emphasize practical skills immediately applicable to the job.... By virtue of the fact that trainers design short term activities, they typically select a discrete array of knowledge, skills and attitudes that experts deem most appropriate to a topic the organization believes is important for its employees to master. ... However, learning then deals with situations out of one's natural context. We believe people learn in the workplace through interactions with others in their daily work environments when the need to learn is greatest.

What then of approaches to developing professional capacities required for designing and working within more elaborate online enhanced and online based learning environments, the new fronts for strategic developments?

\section{The six areas of potential enduring value for teaching and learning}

In order to create and sustain quality e-learning environments of enduring value for teachers and learners, there is a need to appreciate the characteristics of a true learning organisation as applied to educational institutions, such as universities committed to online teaching and learning. Paradoxically, a concentrated focus on the technologies per se can limit possibilities for their creative use. Senge (1990) identifies five characteristics of the learning organisation, including both the capacities to think in systems terms and create new mental models of how the organisation might best undertake its work (the other three being: personal mastery, building shared vision and team learning). Elsewhere, Segrave and Holt (2003) have explored the nature and various dimensions of contemporary learning environments in higher education with their emphasis on the integration of the physical and virtual, and the various features of the virtual within such environments.

We believe that new value will come from the understanding of the need to create new mental models of the newly emerging environments in all their multi-dimensionality. Drawing on the work of Senge, Rylatt (2000, p.20) observes that:

Learning organisations constantly question the assumptions and mindsets of their employees to ensure truth, openness and innovation are championed at the expense of secrecy and politics. Improved performance and potential are achieved by people's willingness to share their mindsets and to state the assumptions and values on which they base their behaviour. This generates a spirit and love for learning that touches the heart and soul of every employee. 
Moreover, these environments are characterised by a set of constructive alignments (Biggs 2003) between curriculum, pedagogy, assessment, and the broader range of media/technology options enacting these educational aspirations (see Corbitt, Holt \& Segrave 2004). In universities, curriculum concerns are often informed by, if they are not the embodiment of, academic teaching staff members' research interests representing even broader synergy between research and teaching. Increasingly, we are seeing in our own University extended and wholly online developments focusing on ICT as a key object of study (in a curriculum sense) in the relevant discipline, and where interesting ideas on curriculum design have their genesis in various lines of research. All of which provide a mindset most conducive to thinking innovatively about the new digital media and online possibilities. New mental models also relate to the capacity to think of the organisation as operating as a set of interrelated systems, as illustrated in Figure 2, where the ' $a$ 's stand for the five key 'alignments' between curriculum, pedagogy, assessment, media/technology mix, and evaluation of impact, while the ' $i$ 's represent seven key types of 'interactions' between teachers, learners and resources. Each learning environment must be seen as reflecting and being a part of other learning environments in different domains. An appreciation of systems thinking and new mental models are not fashionable topics for consideration in formal training programs on using learning management systems, for example. However, it is argued that these matters are central to enabling the creative engagements required for e-learning developments to progress systemically and in ways that nurture the agency of academic teachers.

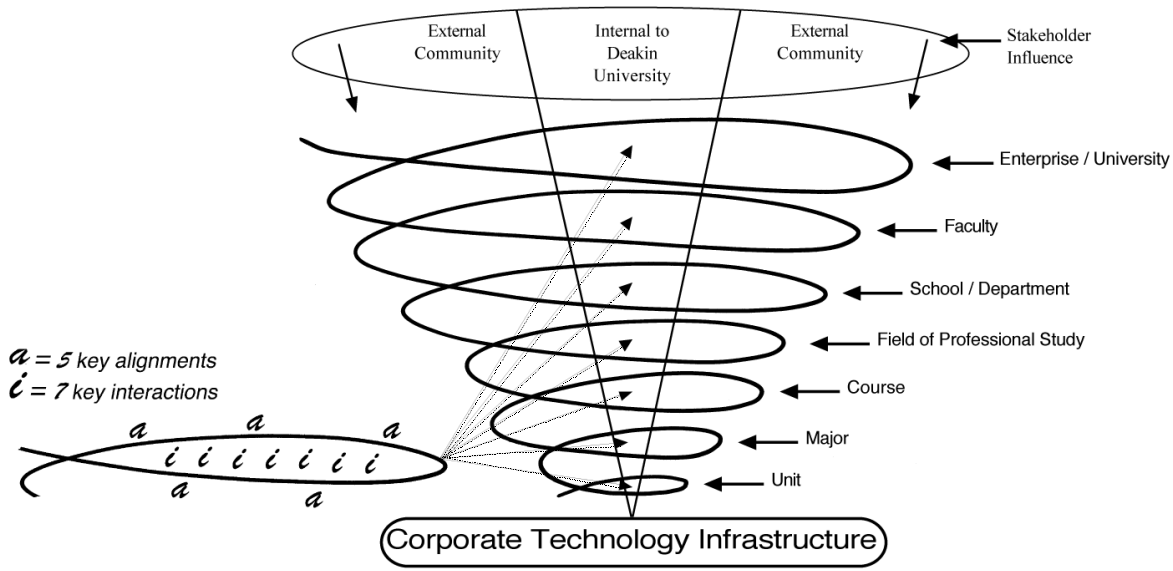

Figure 2: Modelling education design concerns and systems wide impacts of education design Source: Corbitt et al. (2004, p. 10) 
Based on these characteristics of the e-learning 'learning' organisation, Holt and Segrave (2003, pp. 232-3) outlined six areas of potential value adding for teachers and learners in developing and using the new corporate technologies, that we believe form the operational agenda for action in academic professional development: broadened and direct contributions from learning support stakeholders (1); opening up of learning environments to external parties (2); customisation and personalisation of learning experiences (3); sharing of learning resources (4); development of virtual practica (5); ecologically responsive e-learning environments (6).

\section{Conceiving an approach to academic professional development (APD) for online teaching enhancement: Goals, values and design principles}

In order to create enduring value in the six areas mentioned above, a multidimensional approach to academic professional development needs to be developed. The approach would focus on facilitating the ongoing development of academic teaching staff in their understanding and practice of teaching and learning online. The approach should value: the diverse nature and requirements of different participants' contexts; contemporary theory and developments in teaching and learning online; the strength and depth of teaching and learning online across the institution; a self referential, experiential learning design; and individually and socially constructed learning. Any suite of APD support materials, services and environments should reflect these values. Moreover, it is argued that through APD opportunities, participants should be able to engage with, discuss, experience, put into practice and reflect on, pedagogical issues related to teaching and learning online, and relate their understanding and practice of teaching and learning online to appropriate educational principles and key institutional policies.

It is envisaged that academic teachers will be critically reflective designers and creators of their own online teaching and learning environments. Academic teaching staff participating in such APD may be new to tertiary teaching; or new to tertiary teaching at the particular institution; or new to online teaching and learning; or experienced tertiary online educators. In the case of our own University, consistent with the institution's strategic directions and policy, academic teachers are faced with, or immersed within, the task of teaching online at one of the three levels described in the University's Online Technologies in Courses and Units policy (see above). Consequently, participants have a definite need to teach effectively for productive online learning and have some form of meaningful opportunity or context for experimenting with online teaching/learning practices. 
In order to facilitate the development of academic staff as effective online teachers, institutions must design and enact a multi-faceted, supportive and responsive APD environment. This should be integrated with, and enhance, teaching and learning development resources and approaches. We envisage APD undertaken through facilitated, peer oriented, explorative and demand led learning experiences. Such APD must create supportive environments drawing on appropriate theories and contemporary practice. The APD environment should be integrated with various levels and types of expert and peer practitioner support at faculty and university levels provided online and through face to face encounters. Participants would work within, draw upon and apply the various APD resources in constructing and working effectively within their own local online environments. Hence, while participants would spend time in APD based exemplar online environments in order to experience different forms of online teaching and learning, the emphasis would be on translating these experiences into their own environments, and constructing and working effectively within these. The ultimate value of APD offerings would lie in the experiences of participants working effectively with their own students, in their own disciplines and in their own context.

\section{The six professional capacities required for designing and operating within online learning environments}

We identify for development six key areas of professional capacity relating to designing and working effectively within online environments, which would be supported by a new APD approach:

1. Designing for learning online: Participants need to engage in systems thinking when designing learning environments and conceptualise 'contemporary' learning environments as including alignments of the physical and the virtual spheres in their institutional contexts. Moreover, they need to explore possible areas of e-learning value informed by an assessment of the characteristics of their own student groups and their curriculum and pedagogical concerns. There should be a capacity to develop an informed plan of action for teaching using information and communication technologies - the tools of contemporary culture.

2. The three Cs: communicating, collaborating and community development online: Participants need to understand the unique nature, characteristics and contributions that online communication can make to student learning vis a vis other forms of in person communication. Skills developed should be in designing and managing online collaborative strategies for appropriate online communication and also in collective and personal publishing online (using 'social 
software'). Staff should participate in online communicative environments and explore these issues in order to inform design decisions and inform ways of practising online.

3. Assessing student learning online: Participants need understanding of assessment purposes and types of assessment, with a focus on four key areas of assessment supported online, viz: objective testing online; assessing group work online; developing and assessing information literacy online; and experientially based assessments online.

Participants should focus on one key form of online assessment and design an online approach that would realise the form of assessment intended.

4. Developing learning resources for online: Participants need an understanding of a range of media/technologies, their sources and possible educational uses, including the benefits of integrative approaches. Through the consideration of a range of cases, participants should develop and/or review the current media/technologies mix in their teaching area with a view to suggesting enhancements associated with the use of digital media, via the mapping of learning resources, and new styles of learning guides for students.

5. Experiential learning online: Participants need an understanding of the various purposes and forms of experiential learning and how they are being supported by ICTs, with a special focus on supporting work placements integrated with the academic curriculum. Through the consideration of a range of cases illustrating the uses of ICTs in supporting work placements, participants would develop a plan of action for the use of ICTs in their own or another relevant work placement context.

6. Continuous quality improvement online: Participants need an understanding of 'lessons learnt' through various ICT evaluations and research, and quality assurance (QA), and continuous quality improvement (CQI) principles, criteria and guidelines relating to online teaching and learning. Using these lessons, and QA and CQI, participants would design and/or conduct a plan of action for evaluating and improving the impact of their online environment on student learning.

\section{The six strategic APD initiatives for enhancing professional capacities}

The following initiatives constitute the essential ingredients of an online enhanced knowledge management system to capture and support the 
'learning' organisation's learning about its own good practices, in order to enhance over time, the online teaching and learning quality: exemplars through storytelling of cases of innovative online teaching practices (1); demonstrations of exemplar developments (2); promoting, developing and supporting excellent online teachers (3); incorporating capacity development in formal courses in higher education (4); developing interactive and evolving supportive environments (5); integrating academic professional development with course renewal and redevelopment (6).

This is consistent with leading practices in the commercial world and particularly in professional service firms dealing with knowledge intensive products. Peters (1992, pp. 382-412) highlights the importance of more formally managing the bodies of knowledge created by the organisation, with particular reference to the knowledge intensive work of professional service firms like management consultancies. Professional consultants need at their fingertips the collective learnings of all staff in their organisation, to maximise their impact for the benefit of their clients. Consistent with this development, it can be argued that those in professional development roles in universities committed to e-learning need at their finger tips the stories of online teaching successes, so as to enhance their work with academic teaching staff when exploring and pursing new possibilities. These stories can also be shared directly among academic teaching staff in their own collegiate deliberations. Easy online access to stories that resonate with academics' needs, support academic teaching staff members' agency in shaping their desired futures. The University's proposed gateway for its 'knowledge management system structure' is to be developed as the Deakin Teaching and Learning Portal and will encompass exemplars, student evaluation feedback, general guidance and support, etc.

\section{Initiative one: Exemplars through storytelling of cases of innovative online teaching practices}

'An exemplar is a creative piece of work that is based on experience' (McDrury and Alterio 2003, p. 103). Through an APD initiative (University and faculty funded), academic staff members have been nominated for an Online Teaching and Learning Fellowship (OTLF) Program in 2003-2004 to develop exemplar online environments using the University's new LMS, and to support staff in the effective educational use of the system (OTLF is considered further below). In addition to the creation and dissemination of the online developments pursued by the Fellows, it was decided that the codification of their exemplar work (in the form of a portfolio of cases) of innovative online teaching practices would be highly desirable. The overarching goal of the Fellowship exemplar initiative was to compile a collection of case studies that support, influence, inform and profile the 
design and teaching of online courses at the University and to showcase developments to external parties. In 2004, the University provided further strategic APD funding to expand the case portfolio beyond the Fellows' work to other major online developments of interest across the University. The objectives of the case portfolio were to: provide exemplars of quality online pedagogical design and practices; provide a 'Just In Time Training' (JITT) pedagogical and technical resource for those new to major online teaching developments; provide a profile of online design and teaching at the University; and help influence and meet policy imperatives.

The assumptions underpinning the case portfolio were the following: the audience will range from academics new to online teaching and learning, to those experienced in it; the audience will have a minimum basic level of information technology literacy (consistent with the Deakin University Code of Good Online Practice); case studies will be used in traditional professional development settings, as independent and group focussed JITT and in presentations to profile online teaching and learning at Deakin; case studies will be integrated with other training and professional development resources (such as 'step by step' technical training material); case studies need not necessarily be of 'complete' courses (i.e. one designteach-evaluation iteration); case studies will be highly flexible.

Importantly, each case study has been conceived and developed as a complete 'story' and is able to 'stand alone' for professional development purposes. The cases, as a storytelling exercise, have covered the aims and context of the case situation, the planning and building of the online environment, the actual teaching of the unit, and reflections on the success of the development, proposed changes, and online teaching and learning possibilities for the future. In an environment requiring trust among staff, the cases have a high level of credibility with academic teachers speaking of their experiences to their peers. This seems to be important in winning the 'hearts and minds' of those embarking for the first time on significant online developments. The cases have been indexed to provide appropriate sections, which can be taken independently, and they are flexible to alternative structures and technology. Peters (1992, p. 385) observes that, "Most talk about "learning organisations" is maddeningly abstract or vague - and perpetually falls short on the specifics'. We believe the continuing initiative creating a Portfolio of Contemporary Cases of Innovative Online Teaching Practices (see Figure 3) is a concrete example of how to progress the learning organisation ideal as it applies to online teaching and learning developments. We would like it to benefit from knowledge gained about elearning in other universities, and also to contribute to learning in those organisations as part of inter-institutional collaborative arrangements. 


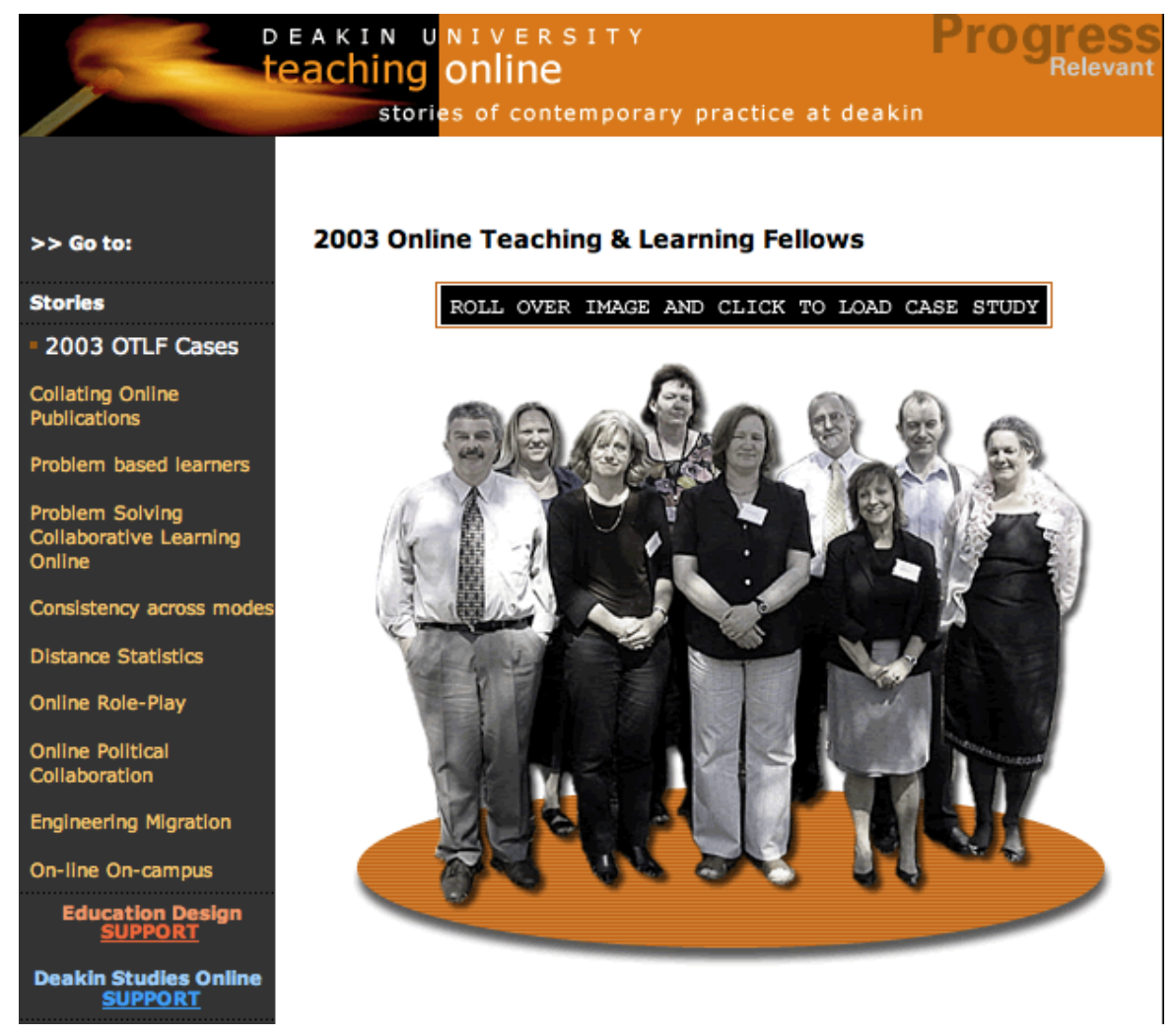

Figure 3: The website for online teaching and learning cases prepared by academic staff in the Fellowship program

While it contains stories of particular practices in particular discipline contexts, it also needs to be viewed from a number of additional perspectives. Beyond the discipline view lies teaching staff members' interests in examining key practice areas in online teaching by academic study entity (ie. unit, major, course level), level of academic study (ie. commencing undergraduate, advanced undergraduate, postgraduate coursework, professional doctorate), size of student cohort (less than 50, $50-100,101-500,501-1000$, greater than 1000) by mode of delivery (ie. on campus, off campus, international, mixed mode), by key educational function (ie. communication and collaboration, assessment, materials design and delivery), by pedagogy ( eg. problem based learning, project based learning, case based learning, workplace based learning) and by related discipline/professional field developments. 


\section{Initiative two: Demonstrations of exemplar developments}

Demonstrations of online teaching innovations during in person presentations are a major complementary strategy to the provision of online resources. These demonstrations can be pre-planned and undertaken in formal university settings. For example, the showcasing of online developments at Deakin over 2003-2004 occurred through an Online Teaching and Learning Conference day sponsored by the Vice-Chancellor, an end of year Online Teaching and Learning Fellowship Seminar, a University wide education design/development forum, inter-institutional gatherings, and presentations led by the PVC (Online Services) involving exemplars organised according to ICTs used in support of student graduate attributes. In addition to these formal demonstration events lie myriad informal opportunities to show and talk about new developments in the context of course and unit redevelopments. These are often small scale and informal gatherings but probably represent a large slice of the overall APD efforts of the institution, representing the proverbial large submerged iceberg. In total time, formal showcasing of exemplars is the small but visible tip of ICT demonstrations. These initiatives are, however, not mutually exclusive. Planned, formal showcasing should in turn be designed to stimulate informal kinds of local showing, telling and sharing sessions tied directly with the teaching development work that has to be done.

\section{Initiative three: Promoting, developing and supporting excellent online teachers}

Excellent online teachers, or put more appropriately, excellent teachers who use digital media and online technologies effectively in their students' learning experiences, need to be nurtured along with their codified online teaching practices. Overall commitment to developing excellent people can be enabled through strategies like the Online Teaching and Learning Fellowship Program (mentioned above), new and expanded teaching achievement awards at faculty and university levels giving more staff more opportunities to apply on the basis of online teaching innovation and effective practices, and probation and promotion schemes taking greater account of University strategic directions in e-learning. The requirement of developing a teaching portfolio of activities and accomplishments organised in some coherent philosophical way is becoming widespread in support of continuing appointment, promotion on the basis of teaching excellence, and in the completion of courses like a graduate certificate in higher education. Increasingly, the demonstration of teaching excellence is requiring evidence of an all round commitment to scholarship in teaching. For online teaching, this means greater attention being paid to supporting academic staff in undertaking research, evaluation and publication in the 
field of educational technology. In an APD sense, this is critical in providing knowledge feedback into the organisation to help improve its practices. Any strategic, so called APD initiative can no longer afford merely to provide support for local practice development per se. It must lead to more transferable knowledge accessible and usable across the organisation. Hence, the reason why research, publication and the cases were so strongly supported as integral to our University's Online Teaching and Learning Fellowship Program.

\section{Initiative four: Incorporating capacity development in formal courses on higher education}

Deakin University has mandated the study of a Graduate Certificate in Higher Education, offered through our Faculty of Education, for all new continuing academic staff appointed by Deakin who do not have at least five years of equivalent full time tertiary teaching experience and the same or a similar qualification. The mandating of this qualification provides a unique opportunity to incorporate the University's strategic directions in online teaching and learning within the pedagogical design and operation of this course.

\section{Initiative five: Developing interactive and evolving supportive environments}

The stories being told in the portfolio of innovative, online teaching cases are pre-determined and formally presented. There is a need to augment this pre-determined storytelling by more spontaneous discussions about them, and a sharing of other examples, vignettes, etc. Web publishing technologies like blogs (web logs), wikis ('wiki-wiki' is derived from the Hawaiian term for 'quick'), and RSS ('Rich Site Summary' or 'Really Simple Syndication') can excel in facilitating the sharing and celebration of successful praxis, as well as offering opportunities for self organised development (Fielder, 2003) and research (Paquet, 2002). If we are to avoid 'mechanistic, rote' approaches to extended and wholly online unit offerings, we need individual and group communication technologies that enable responsive and flexible forms of APD support and professional capacity building. There are certain pressing issues that are best examined using more dynamic approaches providing greater interactivity. During the 2003 Online Fellowship program, for example, as part of robust, small group, in person discussions, the following issues were examined, which would be suitable for ongoing deliberation using appropriate online technologies:

- Where does/should online learning fit in undergraduate programs? 
- Should special undergraduate units be developed to satisfy the requirement that all students study a unit fully online, or should existing units be modified or offered as they are? Should there be discipline wide or university wide core units?

- In resource rich, complex learning environments what should be done to help students get started and progress effectively through the semester? How are instructions/directions best delivered?

- Who should design and build online learning environments? Will there be a contingency based approach or a general policy?

- What can be done to counter the view that 'online units manage themselves'?

The value of the Fellowship was in part related to it promoting crossfaculty and cross-divisional teamwork, supportive of a broader range of collegial interactions and laying the foundations of a Deakin community of professionals, collectively committed to enhancing the use of ICT in teaching and learning.

\section{Initiative six: Integrating academic professional development with course renewal and redevelopment}

APD needs to be seen as an integral part of the whole curriculum design, review and renewal process. The development of the six online professional capacities must in turn be situated within the broader curriculum development context. For example, the cases of innovative online teaching should be drawn upon in the curriculum design process for future extended and wholly online unit developments, and a key indicator of their value would lie in their being used for this purpose. There is a danger that APD related to online developments is separated from general APD relating to improving tertiary teaching and learning. The Graduate Certificate in Higher Education at Deakin is one key initiative of convergence of online with general teaching/learning concerns.

Another relates to the establishment of a Strategic Teaching and Learning Grant Scheme (STALGS) aimed at supporting projects focusing on: improving the quality and/or quality assurance processes in relation to teaching and learning; innovations of teaching/learning of broad application; improvements in graduate outcomes, retention and/or progression rates; creating new local or international collaborations in teaching/learning; improvements in the use of technology; improvements in implementing graduate attributes; improvements in relationships and/or collaboration with government, industry and other stakeholders; demonstrating externally the University's leadership in teaching/learning; and better positioning the University to attract top students. A number of applications to date have featured online developments and associated 
APD implications, but all were required to locate 'online' initiatives within the University's broader teaching and learning plans, policies and central issues.

\section{Conclusion}

APD must be conceived and enacted in ways where staff members are overtly supported by their faculties and their university as a whole. Excellent teaching needs to be a key to the promotion of academic staff, overtly built into performance appraisal schemes, more widely and proactively recognised as an important issue. Our $6^{\text {three }}$ model for developing academic professional capacities is an effective APD model, grounded in a strategic view of the University as a learning organisation committed to allowing its staff to engage pedagogically with the online teaching and learning environment - and to own that environment. Moreover, staff need to be able to be creative in, benefit from the use of, feel well supported by, and have positive experiences with the online environment. Staff need to be able to extend their experiences in teaching and learning online. 'Inspired individuals' need to be encouraged and innovation needs to be fostered. All this demands new approaches to APD to encourage excellence in pedagogy online and academic teacher agency, an uncomfortable but ultimately more productive context for University staff development initiatives than the (more IT product focused) training efforts that often take centre stage.

\section{References}

Biggs, J. (2003). Teaching for Quality Learning at University What the student does. Buckingham: SRHE \& Open University Press.

Corbitt, B., Holt, D.M. \& Segrave, S. (2004). From product centricism to systemswide education design: Making corporate systems work for the learning organisation. Paper presented at The 8th Pacific-Asia Conference on Information Systems (PACIS), 'Information Systems Adoption and Business Productivity', Shanghai, China.

'Deakin Online' Management Plan 2003-2007, Deakin University: http:/ / theguide.deakin.edu.au/ [viewed 19 July 2004]

Deakin University. Code of Good Online Practice, Deakin University: http:/ / theguide.deakin.edu.au/ [viewed 19 July 2004]

Deakin University. Deakin Studies Online Support. [viewed 2 April 2004]. http://www.deakin.edu.au/teachlearn/dso/index.php

Deakin University Online Technologies in Courses and Units Policy, Deakin University: [viewed 19 July 2004]. http:/ / theguide.deakin.edu.au/ 
Deakin University Operational Plan 2004, Deakin University: [viewed 19 July 2004] http://www.deakin.edu.au/vc/operational_plan.php

Deakin University Strategic Plan. Taking Deakin University Forward 2004, Deakin University: [viewed 19 July 2004]. http://www.deakin.edu.au/vc/strategic_plan.php

Department of Employment, Education, Training and Youth Affairs (1997). Managing the Introduction of Technology in the Delivery and Administration of Higher Education, Fujitsu Centre, Australian Graduate School of Management, The University of New South Wales. http:/ / www.dest.gov.au/archive/highered/eippubs/eip9703/front.htm

Fielder, S. (2003). Personal Webpublishing as a reflective conversational tool for self-organized learning. In T. N. Burg (Ed), Blogtalks. (pp. 190-216) Wien: Libri.

Holt, D.M., Rice, M., Segrave, S. \& Thompson, D. (1997), The case of the case: The interplay between research and practice on the web. In T. Evans, D. Thompson \& V. Jakupec (Eds), Research In Distance Education 4, Revised papers from fourth Research in Distance Education conference. (pp. 18-33). Deakin University Press, Deakin University.

Holt, D.M. \& Thompson, D.J. (1998). Managing information technology in open and distance higher education. Distance Education, 19(2), 197-227.

Holt, D.M., Rice, M., Smissen, I. \& Bowly, J. (2001). Towards institution-wide online teaching and learning systems: Trends, drivers and issues. In G. Kennedy, M. Keppell, C. McNaught \& T. Petrovic (Eds), Meeting at the Crossroads: Proceedings 18th ASCILITE Conference. (pp. 271-80). The University of Melbourne. http://www.ascilite.org.au/conferences/melbourne01/pdf/papers/holtd.pdf

Holt, D.M. \& Segrave, S. (2003). Creating and sustaining quality e-learning environments of enduring value for teachers and learners. Interact: Integrate: Impact: Proceedings 20th ASCILITE Conference, pp. 226-235. The University of Adelaide, 7-10 December. http://www.ascilite.org.au/conferences/adelaide03/docs/pdf/226.pdf

Marsick, V.J. \& Watkins, K. E. (1990). Informal and incidental learning in the workplace. London: Routledge.

McDrury, J. \& Alterio, M. (2003). Learning through Storytelling in Higher Education Using Reflection and Experience to Improve Learning. Kogan Page: London.

Paquet, S. (2002). Personal knowledge publishing and its uses in research. http:/ / www.knowledgeboard.com/cgi-bin/item.cgi?ap=1\&id=96934 [viewed 1 July 2004].

Peters, T. (1992). Liberation Management Necessary Disorganisation for the Nanosecond Nineties, London: Macmillan.

Rylatt, A. (2000). Learning Unlimited Practical Strategies for Transforming Learning in the Workplace of the 21st Century, New South Wales: Business + Publishing. 
Segrave, S. \& Holt, D.M. (2003). Contemporary learning environments: Designing e-learning for education in the professions, Distance Education, 24(1), 7-24.

Senge, P. (1990). The Fifth Discipline: The Art E Practice of The Learning Organisation, New York: Doubleday Currency.

This article received an Outstanding Paper Award at ASCILITE 2004, gaining the additional recognition of publication in AJET (with minor revisions). The reference for the Conference version is:

Segrave, S., Holt, D. \& Farmer, J. (2004). The 6 by the power of 3 model for enhancing academic teachers' capacities for effective online teaching and learning: Benefits, initiatives and future directions. In R. Atkinson, C. McBeath, D. Jonas-Dwyer \& R. Phillips (Eds), Beyond the comfort zone: Proceedings 21st ASCILITE Conference (pp. 821-830). Perth, 5-8 December. http://www.ascilite.org.au/conferences/perth04/procs/segrave.html

Stephen F. Segrave, Dale M. Holt and James N. Farmer Teaching and Learning Support Unit, Learning Services Deakin University, Geelong Vic 3217, Australia

stephen.segrave@deakin.edu.au,dale.holt@deakin.edu.au, james.farmer@deakin.edu.au 